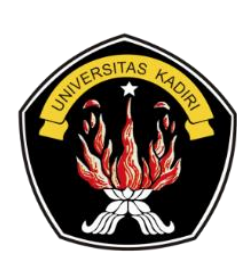

Tersedia secara online di http://ojs.unik-kediri.ac.id/index.php/jatiunik/issue/view/76

\title{
Kriteria Identifikasi Bahaya, Penilaian Dan Pengendalian Risiko Departemen Fabrikasi PT. Unindo Pasifik
}

\author{
Poniman $^{* 1}$, Sri Amaliah Mandati ${ }^{2}$ \\ ${ }^{1,2}$ Program Studi Teknik Industri, Universitas Muhammadiyah Surabaya \\ Email : poniman@ft.um-surabaya.ac.id
}

\section{Informasi Artikel}

Riwayat Artikel :

Received : 24 - Juli - 2020

Revised : 9 -Oktober-2020

Accepted : 13 -Oktober - 2020

Kata kunci :

Hazard

Occupational Health And

OTP

Risk Assessment

Safety

\section{A b s tract}

Health and safety risk assessment of PT Unido Pasifik Fabrication department to create a safe and efficient and productive work environment. The fabrication department is the main pillar of company support. The purpose of this study was to analyze the potential hazards in the Production department especially the PT Unindo Pasifik Fabrication Department. In addition this study aims to determine the relationship of knowledge of workers about the potential danger with the behavior of the use of personal protective equipment. This research is an observational descriptive study in which the object of research is the machine, attitude or behavior of the workforce, work processes and work environment. Based on hazard identification, risk assessment and control, there are several hazards and risks that occur with tolerable risk, moderate risk and sustainable risk criteria. Hazard control has been carried out at PT. Unindo Pasifik that is administrative control and the provision of personal protective equipment (PPE). And while the Objective, Target and Program (OTP) are set namely reducing work accidents and reducing occupational diseases in the Fabrication department.

\begin{abstract}
A b s t r a k
Didalam penilaian risiko kesehatan dan keselamatan departemen Fabrikasi PT Unido Pasifik untuk menciptakan lingkugan kerja aman dan efisien serta produktif. Departemen fabrikasi merupakan penopang kegitaan perusahaan yang utama. Tujuan penelitian ini untuk menganalisis potensi bahaya di bagian Produksi khususnya Departemen Fabrikasi PT Unindo Pasifik. Selain itu penelitian ini bertujuan untuk mengetahui hubungan pengetahuan pekerja tentang potensi bahaya dengan perilaku penggunaan alat pelindung diri. Penelitian ini merupakan penelitian deskriptif observasional dimana Objek penelitian adalah mesin, sikap atau perilaku tenaga kerja, proses kerja dan lingkungan kerja. Berdasarkan identifikasi bahaya, penilaian dan pengendalan risiko terdapat beberapa bahaya dan risiko yang terjadi dengan kriteria tolerable risk, moderate risk dan sustainable risk. Pengendalian bahaya sudah dilakukan di PT. Unindo Pasifik yaitu pengendalian bersifat administrative \&
\end{abstract}


penyediaan alat pelindung diri (APD). Dan sedangkan Objective, Target dan Program (OTP) yang ditetapkan yaitu mengurangi kecelakaan kerja dan diharapkan dapat mengurangi penyakit yang ditimbulkan akibat kerja di deprtemen fabrikasi tersebut.

\section{Pendahuluan}

Program Penerapan Keselamatan dan kesehatan kerja pada perusahaaan harus diperhatikan dan didukung oleh manajemen serta seluruah karyawan. Agar program ini dapat berjalan sesuai dengan harapan. Tanpa ada dukungan dari semua pihak program keselamatan dan Kesehatan tidak akan berjalan dan jutru akan timbul kecelakaan kerja yang akibatnya dapat merugikan karyawan maupun perusahaan itu sendiri. Kerugian akibat kerja bisa berupa kerugian material maupun kerugian immaterial akibat dari kecelakaan kerja, sedangkan kerugian bagi perusahaan yaitu kehilangan tenaga kerja sehingga produksi berkurang sehingga target produksi dan delivery ke konsumen terhambat akibat dari kecelakaan. Oleh karena itu perushaan sudah seharusnya untuk menerapakn K3 di lokasi kerja. Dan menurut[1] jika terjadinya kecelakaan perusahaan mengalami kerugian dan penurunan hasil produksi dikarenakan kurangnya tenaga kerja.

PT. Unindo Pasifik merupakan perusahaan yang bergerak dalam bidang manufacturing dan fabrikasi. Perusahaan ini memiliki dua departemen yaitu departemen rekayasa industri dan departemen fabrikasi. Salah satu produk yang dihasilkan oleh departemen ini adalah pembuatan conveyor dan pebuatan tangki. Dalam penelitian ini akan lebih menitik beratkan pada cara pecegahan atau pengurangan resiko kecelakaan kerja pada system kerja. Analisa K3 yang dilakukan dalam penelitian ini dengan memperhatikan berbagai faktor yaitu subyektifitas pekerja terhadap keluhan K3 pada saat bekerja dan memperhatikan pengaruh lingkungan seperti kebisingan dan pencahayaan pada departemen fabrikasi.

Salah satu untuk memenangkan persaiangan bebas kesehatan dan keselamatan kerja merupakan penentu persyaratan yang harus dipenuhi oleh Industri di [1]. Masalah keselamatan dan kesehatan kerja merupakan masalah yang ada pada kegitan-kegitan Industri manufatur maupun bidang industri lainya, Oleh karena itu untuk mengurangi risisko kecelakaan kerja perlu dilakukan evaluasi atau solusi dalam mengurangi kecelakan kerja itu sendiri dengan cara melakukan pengendalian potensi bahaya risiki kecelakaan. Oleh sebab itu perusahaan dalam bidang manufaktur harus Sistem Manajemen Keselamatan Kesehatan Kerja (SMK3). PT Unindo Pasifik telah menerapkan SMK3 baik secara administrative maupun dalam penyediaan APD. Tujuan dari penelitian adalah bagaimana cara untuk mengurangi kecelakaan kerja dan mengurangi penyakit akibat kerja departemen Fabrikasi. PT. Unindo Pasifik memiliki HSE Officer sebagai pelaksana dan pemantau kebijakan penerapan Sistem K3.

Hasil Penelitian terdahulu [2] melakukan penilaian resiko K3 dalam kegiatan analisis uranium dengan Titroprosesor berada pada peringkat A, dengan skala antara $0-24$ yang berarti risiko dapat diterima. Sedangkan langka-langkah pengendalian yang dilakukan dinilai efektif. Menurut penelitian [3] menyatakan bahwa jenis kegiatan yang memiliki risk rating number tertinggi adalah tersandung sparepart/ alat bengkel dengan risk rating number 
sebesar 8, tersandung hand tool/alat kerja dengan Risk rating number sebesar 8 dan menghirup asap pembakaran bahan bakar dengan Risk rating number sebesar 8. Dan dari ketiga jenis kegiatan tersebut dikategorikan tingkat risiko prioritas menengah/risiko signifikan masuk pada indeks III B. Dengan menggunakan Fishbone dengan memberikan rekomendasi yaitu kegiatan dilaboratorium secara hati - hati dan selalu menggunakan APD serta mematuhi aturan dan mengetahui fungsi dari masing - masing sparepart, peralatan kerja dan benda - benda berbau tajam. Penelitian yang dilakukan oleh [4] terdapat Bahaya yang teridentifikasi di Bengkel Konstruksi Bodi Kendaraan Jurusan Teknik Otomotif Fakultas Teknik Universitas Negeri Yogyakarta sejumlah 41 bahaya. Bahaya tersebut meliputi 5 bahaya pada penanganan material, 4 bahaya pada peralatan tangan, 3 bahaya pada pengamanan mesin, 4 bahaya pada desain tempat kerja, 3 bahaya pada pencahayaan, 9 bahaya pada lingkungan kerja, 2 bahaya pada zat berbahaya dan beracun, 8 bahaya pada fasilitas kesejahteraan dan 3 bahaya pada organisasi kerja. Dan penilaian risiko atau bahaya di Bengkel Konstruksi Bodi Kendaraan Jurusan Teknik Otomotif Fakultas Teknik Universitas Negeri Yogyakarta yaitu kategori bahaya Extreme (Ekstrim) sejumlah 4 bahaya, kategori High (Tinggi) sejumlah 16 bahaya, kategori Moderate (Sedang) 18 bahaya dan kategori Low (Rendah) sejumlah 3 bahaya. Sehingga Pengendalian risiko terhadap bahaya yang ada di Bengkel Konstruksi Bodi Kendaraan Jurusan Teknik Otomotif Fakultas Teknik Universitas Negeri Yogyakarta diprioritaskan pada bahaya yang masuk dalam kategori Extreme terlebih dahulu. Potensi bahaya kategori Extreme jika sudah di lakukan pengendalian secara keseluruhan dan dinyatakan aman, pengendalian risiko bahaya dapat dilanjutkan pada bahaya kategori High, Moderate, dan Low pada tahap paling akhir.

\section{Tinjauan Pustaka}

\subsection{Keselamatan dan Kesehatan Kerja}

Dalam buku kesehatan lingkungan dan K3 [5] dijelaskan yaitu:

1. Kesehatan kerja merupakan suatau pemikiran dan upaya untuk menjamin keutuhan dan kesempurnaan baik jasmani maupun rohani tenaga kerja pada khususnya, dan manusia pada umumnya, hasil karya dan budaya untuk menuju masyarakat yang adil dan makmur.

2. Ridley dalam [1], keselamatan dan kesehatan kerja merupakan suatu kondisi dalam pekerjaaan yang sehat dan aman baik bagi pekerjanya, perusahaan maupun masyarakat dan lingkungan sekitar tempat kerja tersebut.

3. Secara filosofi (PP 50 Tahun 2012), keselamatan kesehatan kerja adalah suatu pemikiran dan upaya demi terjaminnya keadaan, keutuhan dan kesempurnaan baik jasmani maupun rohani manusia serta hasil karya dan budaya yang bertujuan untuk kesejahteraan manusia pada umumnya dan tenaga kerja pada khususnya.

4. Secara ilmuan (Depnaker RI, 1991), keselamatan kesehatan kerja adalah ilmu pengetahuan dan penerapan yang khusus mempelajari tentang cara-cara pencegahan dan penanggulangan atas kecelakaan yang terjadi di tempat kerja.

5. Secara hukum (Depnaker RI, 1991), keselamatan kesehatan kerja adalah perlindungan agar tenaga kerja senantiasa dalam keadaan selamat dan selama melakukan pekerjaan di tempat kerja selalu mengamankan sumber bahaya dan proses produksi serta dapat bekerja lebih efisien. 


\subsection{Sistem Manajemen Keselatamatan dan Kesehatan Kerja}

Sistem manajemen secara keseluruhan yang meliputi struktur organisasi, perencanaan, tanggung-jawab, pelaksanaan, penerapan, pencapaian, pengkajian dan pemeliharaaan kebijakan keselamatan dan kesehatan kerja dalam rangka pengendalian resiko yang berkaitan dengan kegiatan kerja guna terciptanya tempat kerja yang aman, efesien dan produktif. Sedangkan tempat kerja adalah tempat atau ruang, tertutup atau terbuka, bergerak atau tetap, dimana tenaga kerja bekerja, atau yang sering dimasuki tenaga kerja untuk keperluan suatu usaha dan dimana terdapat sumber atau sumber-sumber bahaya baik di darat, di dalam tanah, di permukaan air, di dalam air, di udara yang berada dalam wilayah kekuasaan hukum Republik Indonesia. Menurut [2] SMK3 wajib dilaksanakan oleh pengurus, pengusaha dan seluruh tenaga kerja sebagai satu kesatuan. Setiap perusahaan wajib menerapkan SMK3 di perusahaannya, bertujuan untuk [6]:

a. Meningkatkan efektifitas perlindungan keselamatan dan kesehatan kerja yang terencana, terukur, terstruktur, dan terintegrasi;

b. Mencegah dan mengurangi kecelakaan kerja dan penyakit akibat kerja dengan melibatkan unsur manajemen, pekerja/buruh, dan/atau serikat pekerja/serikat buruh;

c. Menciptakan tempat kerja yang aman, nyaman, dan efisien untuk mendorong produktivitas.

Penerapan SMK3 wajib berlaku bagi perusahaan yang [6]:

a. Mempekerjakan pekerja/buruh paling sedikit 100 (seratus) orang; atau

b. Mempunyai tingkat potensi bahaya tinggi.

Penerapan SMK3 dilakukan meliputi[6] :

a. Penetapan kebijakan K3;

b. Perencanaan K3;

c. Pelaksanaan rencana K3;

d. Pemantauan dan evaluasi kinerja K3;

e. Peninjauan dan peningkatan kinerja SMK3.

Rencana K3 disusun dan ditetapkan oleh pengusaha dengan mengacu pada kebijakan K3 yang telah ditetapkan. Dalam menyusun rencana K3 pengusaha harus mempertimbangkan:

a. Hasil penelaahan awal;

b. Identifikasi potensi bahaya, penilaian, dan pengendalian risiko;

c. Peraturan perundang-undangan dan persyaratan lainnya;

d. Sumber daya yang dimiliki

Penerapan Sistem Manajemen Keselamatan dan Kesehatan Kerja (SMK3) dijelaskan pada peraturan pemerintah yaitu PP RI No 50 Tahun 2012 bahwa terdapat beberapa aspek SMK3, yaitu meliputi: penetapan kebijakan K3, perencanaan K3, pelaksanaan K3, pemantauan serta evaluasi K3, dan peninjauan serta peningkatan K3 [6]. Menurut Peraturan Menteri Tenaga Kerja Republik Indonesia, yaitu Permenaker No.05/MEN/1996, yang menyatakan bahwa Sistem Manajemen Keselamatan dan Kesehatan Kerja (SMK3) merupakan bagian dari sistem manajemen secara keseluruhan, yang meliputi struktur organisasi, perencanaan, tanggung jawab, pelaksanaan, prosedur, proses, dan sumber daya yang dibutuhkan bagi pengembangan, penerapan, pencapaian, pengkajian, dan pemeliharaan kebijakan keselamatan dan kesehatan kerja dalam pengendalian resiko yang 
terjadi seminimal mungkin berkaitan dengan kegiatan kerja guna terciptanya tempat kerja yang aman efisien dan produktif [7].

\subsection{Indikator Keselamatan}

Menurut Suma'ur dalam jurnal Bambang Suharjo dan Mohamad Arifin yang berjudul Analisa Risiko Dan Implementasi Metode HIRARC Pada Satuan Penyelam Di Dislambair Koarmatim adapun indikator - indikator keselamatan kerja meliputi [8], [9], [10] :

1. Tempat Kerja Tempat kerja merupakan lokasi dimana para karyawan melaksanakan aktifitas kerjanya.

2. Mesin dan Peralatan Mesin dan Peralatan adalah bagian dari kegiatan operasional dalam proses produksi yang biasanya berupa alat - alat berat dan ringan

\subsection{Indikator Kesehatan Kerja}

Menurut Gary Dessler dalam [11]. Kepemimpinan Keselamatan Kerja dijelaskan bahwa indikator kesehatan kerja terdiri dari :

1. Keadaan dan Kondisi Karyawan adalah keadaan yang dialami oleh karyawan pada saat bekerja yang mendukung aktivitas dalam bekerja.

2. Lingkungan kerja adalah lingkungan yang lebih luas dari tempat kerja yang mendukung aktivitas karyawan dalam bekerja

\subsection{Definisi Bahaya}

Bahaya merupakan segala sesuatu situasi atau tindakan yang memiliki potensi menimbulkan kecelakaan atau cidera pada manusia, kerusakan atau gangguan lainnya. Oleh karena itu bahaya perlu dilakukan upaya pengendalian agar bahaya tidak menimbulkan akibat yang merugikan[12]. Sifat bahaya merupakan sifat yang melekat dan menjadi bagian dari suattu zat, sisitem, kondisi atau peralatan. Sebagai contoh api secara alamiah mengandung sifat panas yang bila mengenai benda atau tubuh manusia dapat menimbulkan kerusakan atau cidera. Dalam buku kesehatan lingkungan dan K3 [5] dijelaskan jenis bahaya dapat diklasifikasikan antara lain [12] meliputi:

a. Bahaya Mekanis

Merupakan bahaya yang bersumber dari peralatan mekanis atau benda yang bergerak dengan gaya mekanik. Baik digerakkan secara manual atau dengan penggerak. Bagian yang bergerak mengandung bahaya, seperti gerakan memotong, menempa, menjepit, menekan, mengebor dan bentuk gerakan lainnya.

b. Bahaya Listrik

Energi listrik dapat mengakibatkan berbagai bahaya, seperti sengatan listrik, konsleting yang menimbulkan kebakaran. Di tempat kerja banyak ditemukan bahaya listrik, baik dari jaringan listrik, peralatan kerja maupun mesin-mesin yang menggunakan energi listrik [12]. Kondisi potensi bahaya, seperti kontak dengan listrik akibat kurang kehatihatian dapat terjadi selama analisis rekayasa, instalasi, pelayanan, tes serta pemeliharaan listrik dan peralatan listrik. Untuk menurunkan pemaparan pada sebagian besar potensi bahaya tersebut tidaklah sulit atau mahal apabila pengamanan dan prosedur keamanan dikenalkan pada tahap rancangan.

c. Bahaya Kimiawi

Merupakan bahaya yang berasal dari bahan yang dihasilkan selama produksi. Bahan ini terhambur ke lingkungan karena cara kerja yang salah, kerusakan atau kebocoran dari peralatan atau instalasi yang digunakan dalam proses kerja. Bahan kimia yang terhambur 
ke lingkungan kerja dapat menyebabkan gangguan lokal dan gangguan sistemik [13]. Jika terjadi bahaya ini maka akan terdapak bahaya kercunan atau iritasi karena sifat bahan kimia seperti asam keras, Kebakaran dan peledakan dan Polusi dan pencemaran lingkungan.

d. Bahaya Fisik

Bahaya fisik merupakan seperti: ruangan yang terlalu panas, terlalu dingin, bising, kurang penerangan, getaran yang berlebihan, radiasi dan lain sebagainya[13]. Sedangkan menurut,[12] bahaya fisik adalah bahaya yang berasal dari faktor-faktor fisik.

\subsection{Proses Kerja}

Proses kerja Menurut Ramli dalam [1] dijelaskan bahwa dalam proses produksi terjadi kontak antara manusia dengan mesin, material dan lingkungan kerja yang diakomodir oleh proses atau prosedur kerja. Kegiatan produksi menggunakan jenis proses yang bersifat fisis atau kimia, misalnya dalam proses pembuatan tangki dan konveyor merupakan proses fisis dan proses kimia seperti pengujian takana dalam tanki. Seluruh proses ini mengandung bahaya, seperti tekanan yang berlebihan atau temperatur yang terlalu tinggi dapat menimbulkan bahaya ledakan atau kebakaran. Proses produksi dibuat melalui sistem dan prosedur operasi yang diperlukan sesuai dengan sifat dan jenis kegiatan. Secara langsung sistem dan prosedur tidak bersifat bahaya, tetapi dapat mendorong timbulnya potensi bahaya. Di dalam proses kerja terdapat sumber-sumber bahaya[1], [14]-[16] yaitu:

a. Manusia

Manusia dapat menjadi sumber bahaya di tempat kerja pada saat melakukan aktivitasnya masing-masing. Misalnya ketika pekerja sedang melakukan pengelasan, maka dalam proses pengelasan tersebut akan menimbulkan berbagai jenis bahaya

b. Peralatan

Peralatan kerja yang digunakan di tempat kerja, seperti mesin, pesawat uap, pesawat angkat, alat angkut, tangga dan lain sebagainya dapat menjadi sumber bahaya bagi manusia yang menggunakannya. Seperti pada penggunaan tangga yang sudah tidak baik atau rusak dapat menyebabkan bahaya jatuh dari ketinggian

c. Material

Material yang berupa bahan baku atau hasil produksi mengandung berbagai jenis bahaya sesuai dengan sifat dan karateristiknya masing-masing. Contohnya seperti material yang berupa bahan kimia mengandung bahaya seperti iritasi, keracunan, pencemaran lingkungan dan kebakaran

d. Proses

Kegiatan produksi di tempat kerja menggunkan berbagai jenis proses yang bersifat fisik atau kimia. Proses produksi yang dilakukan di perusahaan merupakan serangkaian proses majemuk yang cukup rumit. Setiap proses produksi dapat menimbulkan berbagai dampak (risiko bahaya) antara lain paparan debu, asap, panas, bising dan lain sebagainya.

e. Sistem dan Prosedur

Proses produksi di tempat kerja dilakukan melalui suatu sistem dan prosedur operasi yang diperlukan sesuai dengan jenis dan sifat kegiatan masing-masing. Sistem dan prosedur secara langsung tidak bersifat berbahaya, tetapi dapat mendorong timbulnya berbagai jenis bahaya yang sangat potensial) 


\section{f. Unsafe Action Unsafe action}

Tindakan berbahaya dari para tenaga kerja yang mungkin dilatar belakangi oleh berbagai sebab.

\section{g. Unsafe Condition Unsafe condition}

Kondisi yang tidak aman dari mesin, peralatan, pesawat, bahan, proses kerja, lingkungan dan tempat kerja serta sifat pekerjaan dan sistem kerja).

\subsection{Analisa Risiko}

Risiko adalah kombinasi dari kemungkinan terjadinya kejadian berbahaya atau paparan dengan keparahan dari cidera atau gangguan kesehatan yang disebabkan oleh kejadian atau paparan tersebut. Sedangkan manajemen risiko adalah suatu proses untuk mengelola risiko yang ada dalam suatu kegiatan[12]. Risiko adalah manifestasi atau perwujudan potensi bahaya (hazard event) yang mengakibatkan kemungkinan kerugian menjadi lebih besar. Tergantung dari cara pengelolaannya, tingkat risiko mungkin berbeda dari yang paling ringan atau rendah sampai ke tahap yang paling berat atau tinggi. Melalui analisis dan evaluasi semua potensi bahaya dan risiko, diupayakan tindakan minimalisasi atau pengendalian agar tidak terjadi bencana atau kerugian lainnya [17]-[20].

\section{Metode Penelitian}

Jenis Penelitian ini termasuk penelitian Deskriptif. Dilihat dari jenis datanya merupakan penelitian kualitatif. Data kualitatif yaitu data yang didapatkan dari perusahaan bersifat secara lisan maupun tulisan yang bukan bersifat angka, antara lain informasi tentang penggunaan metode untuk melakukan deteksi kecelakaan kerja yaitu menggunakan skala keparahan, skala tingkat pemaparan dan skala kemungkinan risiko [21]. Objek Penelitian Objek penelitian yang diambil penulis adalah area kerja di Departemen Fabrikasi PT Unindo Pasifik.

Data yang digunakan dalam penelitian ini yaitu data primer. Data primer adalah data yang didapatkan langsung dari obyek penelitian dengan mengadakan pengamatan langsung atau wawancara kepada karyawan departemen fabrikasi PT Unindo Paisifik[22]. Data sekunder adalah data yang didapatkan secara tidak langsung melalui penelitian kepustakaan baik melalui dokumen-dokumen atau laporan tertulis serta informasi lainnya yang berhubungan dengan penelitian ini [22]. Adapun metode pengumpulan data yaitu Studi Kepustakaan Pengumpulan data dan pencaharian informasi dilakukan dengan menelaah buku yang terdapat di perpustakaan, dan sumber-sumber lain yang berkaitan dengan penelitian ini. Penelitian Lapangan (Field Research): Observasi yaitu Melakukan penelitian langsung ke lokasi untuk mendapatkan informasi yang diperlukan dan Wawancara yaitu Mengadakan wawancara langsung dengan operator yang ada dilapangan[21]. Metode analisis yang digunakan pada penelitian ini dengan tahapan sebagai berikut :

1. Kriteria Identifikasi jenis pekerjaan

2. Kriteria Identifikasi potensi bahaya

3. Melakukan penilaian risiko keparahan (Severity).

4. Penilaian frekuensi yaitu tingkat keseringan kejadian.

5. Melakukan perhitungan besar nilai risiko kecelakaan 


\section{Hasil dan Pembahasan}

\subsection{Kriteria Bahaya Yang Teridentifikasi}

Terdapat kriterian bahaya teridentifikasi yang dapat dikelompokkan berdasarkan katergori atau tingkatan bahaya dari yang paling berbahaya ke tingkat yang lebih rendah [4] sebagai berikut :

a. Kategori Extreme

1. Kabel listrik yang berserakan setelah kerja

2. Tidak adanya sistem pembuangan asap pengelasan

3. Kotak P3K tidak terawat dan tidak tersedia cukup obat

b. Kategori High

1. Pelindung otomatis tidak terawat dan kondisinya rusak pada peralatan gerinda

3. Alat pemadam kebakaran sulit diakses karena terhalang peralatan dan mesin

4. Tidak terdapat tanda dimana area yang membutuhkan perlindungan perorangan

5. Lantai tidak rata dan terdapat perbedaan ketinggian pada jalur transportasi

6. Pemeliharaan peralatan kurang

7. Penempatan kontrol alat sulit dijangkau oleh pekerja

8. Tidak terdapat lampu lokal atau lampu setempat untuk pekerjaan dengan tingkat kepresisian tinggi

9. Jalur evakuasi sempit dan terhalang benda-benda

10. Area yang berisiko menimbulkan paparan biologi tidak terisolasi (area pengelasan, penggerindaan)

11. Tidak terdapat pemanasan sebelum memulai kegiatan kerja

c. Kategori Moderate

1. Rute transportasi terhalang benda-benda dan rak peralatan

2. Getaran dan kebisingan Power Tool masih cukup tinggi

3. Kursi yang tersedia tidak dapat diatur ketinggianya

4. Tidak terdapat sekat atau pelindung visual antar area kerja

5. Tidak terdapat ruang ganti dan loker yang aman

12. Peralatan pelindung diri sebagian dalam kondisi tidak terawat dan kotor

13. Alat pelindung diri tidak tersimpan dengan baik

14. Tidak terdapat fasilitas istirahat untuk memulihkan dari kelelahan

d. Kategori Low

1. Sumber panas area kerja las tidak terisolasi dengan baik

2. Ventilasi udara di ruang las kurang maksimal

\subsection{Identifikasi Bahaya, Penilaian dan Pengendalian Risiko}

Pengendalian risiko terhadap bahaya yang teridentifikasi dilakukan setelah dilakukan penilaian sebelumnya. Ditempat kerja terdapat beberapa sumber bahaya yang beraneka ragam mulai dari kapasitas bahaya yang rendah hingga bahaya yang tinggi. Oleh karena itu tidak akan dapat mencegah terjadinya kecelakaan jika tidak dapat mengenali bahaya dengan baik dan seksama. Sedangkan jenis bahaya diklasifikasikan menjadi beberapa macam yakni bahaya mekanis, listrik, kimiawi, dan fisik. Dengan menggunakan metode HIRADC dalam melakukan identifikasi bahaya dan penilaian risiko diperoleh bahaya-bahaya yang berpotensi terjadi pada Departemen Fabrikasi sebagai berikut : 
Tabel 1. Identifikasi Bahaya dan Penilaian Risiko

\begin{tabular}{|c|c|c|c|c|c|c|c|c|c|c|c|}
\hline \multirow[t]{3}{*}{ No } & \multirow[t]{2}{*}{ Akifitas } & \multirow[t]{3}{*}{ Rutin } & \multirow[t]{3}{*}{ No rutin } & \multirow[t]{3}{*}{ bahaya } & \multirow[t]{3}{*}{ Konsekuensi } & \multicolumn{3}{|c|}{ Penilaian resiko } & \multirow[t]{3}{*}{ Tingkat resiko } & \multirow[t]{3}{*}{ Pengendalian } & \multirow{3}{*}{$\begin{array}{l}\text { Pengendalian } \\
\text { tambahan }\end{array}$} \\
\hline & & & & & & kemungkinan & Keparahan & Total & & & \\
\hline & & & & & & $\mathrm{a}$ & $\mathrm{b}$ & axb & & & \\
\hline \multirow[t]{6}{*}{1} & $\begin{array}{l}\text { Persiapan } \\
\text { material }\end{array}$ & & & $\begin{array}{l}\text { Tanagn } \\
\text { terjepit }\end{array}$ & $\begin{array}{l}\text { Cidrera } \\
\text { tangan }\end{array}$ & 2 & 2 & 4 & Moderate & $\begin{array}{l}\text { Penggunaan sarung } \\
\text { tangan }\end{array}$ & $\begin{array}{l}\text { Memasang } \\
\text { symbol-simbol } \\
\text { tanda bahaya }\end{array}$ \\
\hline & & & & $\begin{array}{l}\text { Tertimpa } \\
\text { material }\end{array}$ & Cidera kaki & 2 & 1 & 2 & tolerable & $\begin{array}{l}\text { Penggunaan sepatu } \\
\text { safety }\end{array}$ & - \\
\hline & & & & Tersandung & Terkilir - luka & 2 & 1 & 2 & tolerable & $\begin{array}{l}\text { Pengaturan material } \\
\text { ditata dengan rapih }\end{array}$ & - \\
\hline & & & & Terkilir & Memar-luka & 2 & 2 & 4 & Moderate & $\begin{array}{l}\text { Pegaturan } \\
\text { pengangkatan } \\
\text { material }\end{array}$ & - \\
\hline & & & & $\begin{array}{l}\text { Bahaya } \\
\text { ergonomic }\end{array}$ & $\begin{array}{l}\text { Sakit badan } \\
\text { atau } \\
\text { punggung }\end{array}$ & 2 & 2 & 4 & Moderate & $\begin{array}{l}\text { Pengaturan } \\
\text { pengangkatan dan } \\
\text { hindari Gerakan } \\
\text { monoton barang }\end{array}$ & $\begin{array}{l}\text { Penggunaan } \\
\text { manual hendling }\end{array}$ \\
\hline & & & & $\begin{array}{l}\text { Menghirup } \\
\text { debu }\end{array}$ & $\begin{array}{l}\text { Gangguan } \\
\text { pernafasan }\end{array}$ & 2 & 3 & 6 & Substansial & Pengguanan masker & \\
\hline \multirow[t]{4}{*}{2} & Pengelasan & & & Radiasi panas & Iritasi kulit & 2 & 3 & 6 & Substansial & $\begin{array}{l}\text { Penggunaan sarung } \\
\text { tangan safety - aprond }\end{array}$ & $\begin{array}{l}\text { Memebuat intruksi } \\
\text { kerja }\end{array}$ \\
\hline & & & & $\begin{array}{l}\text { Terkena } \\
\text { Percikan api }\end{array}$ & Luka bakar & 2 & 3 & 6 & Substansial & $\begin{array}{l}\text { Penggunaan sarung } \\
\text { tangan safety }\end{array}$ & $\begin{array}{l}\text { Memasang } \\
\text { symbol-simbol } \\
\text { tanda bahaya }\end{array}$ \\
\hline & & & & $\begin{array}{l}\text { Tersengat } \\
\text { listrik }\end{array}$ & Luka bakar & 2 & 3 & 6 & Substansial & $\begin{array}{l}\text { Periksa aliaran listrik } \\
\text { sebelum melakukan } \\
\text { kegiatan kerja }\end{array}$ & - \\
\hline & & & & $\begin{array}{l}\text { Radiasi sinar } \\
\text { las }\end{array}$ & $\begin{array}{l}\text { Ganggungan } \\
\text { penglihatan }\end{array}$ & 2 & 3 & 6 & Substansial & $\begin{array}{l}\text { Penggunaan sarung } \\
\text { tangan safety - kaca } \\
\text { mata las }\end{array}$ & - \\
\hline \multirow[t]{3}{*}{3} & Cutting & & & $\begin{array}{l}\text { Terkena mata } \\
\text { gergaji }\end{array}$ & $\begin{array}{l}\text { Luka pada } \\
\text { tangan }\end{array}$ & 1 & 3 & 3 & Moderate & $\begin{array}{l}\text { Penggunaan sarung } \\
\text { tangan safety }\end{array}$ & $\begin{array}{l}\text { Memasang } \\
\text { symbol-simbol } \\
\text { tanda bahaya }\end{array}$ \\
\hline & & & & $\begin{array}{l}\text { Terkena } \\
\text { serpihan } \\
\text { potongan }\end{array}$ & $\begin{array}{l}\text { Luka pada } \\
\text { tanagan }\end{array}$ & 1 & 3 & 3 & Moderate & $\begin{array}{l}\text { Penggunaan sarung } \\
\text { tangan safety }\end{array}$ & $\begin{array}{l}\text { Memebuat intruksi } \\
\text { kerja }\end{array}$ \\
\hline & & & & $\begin{array}{l}\text { Penggantian } \\
\text { daun gergaji }\end{array}$ & $\begin{array}{l}\text { Luka pada } \\
\text { tangan, }\end{array}$ & 1 & 3 & 3 & Moderate & $\begin{array}{l}\text { Penggunaan sarung } \\
\text { tangan safety }\end{array}$ & $\begin{array}{l}\text { Memasang } \\
\text { symbol-simbol } \\
\text { tanda bahaya }\end{array}$ \\
\hline \multirow[t]{4}{*}{4} & Grinding & & & $\begin{array}{l}\text { Serpihan } \\
\text { material }\end{array}$ & & 2 & 3 & 6 & Substansial & $\begin{array}{l}\text { Penggunaan sarung } \\
\text { tangan safety- kaca } \\
\text { mata safety }\end{array}$ & $\begin{array}{l}\text { Memebuat intruksi } \\
\text { kerja }\end{array}$ \\
\hline & & & & Percikan api & & 2 & 3 & 6 & Substansial & $\begin{array}{l}\text { Penggunaan sarung } \\
\text { tangan dan kaca mata }\end{array}$ & $\begin{array}{l}\text { Memasang } \\
\text { symbol-simbol } \\
\text { tanda bahaya }\end{array}$ \\
\hline & & & & $\begin{array}{l}\text { Tersandung } \\
\text { kabel }\end{array}$ & & 2 & 3 & 6 & Substansial & $\begin{array}{l}\text { Rapikan setelah } \\
\text { melakukan pekerjaan }\end{array}$ & - \\
\hline & & & & $\begin{array}{l}\text { Tersengat } \\
\text { listrik }\end{array}$ & & 1 & 3 & 3 & Moderate & Periksa aliran listrik & - \\
\hline \multirow[t]{3}{*}{5} & $\begin{array}{l}\text { Mesin } \\
\text { press }\end{array}$ & & & $\begin{array}{l}\text { Tangan } \\
\text { terjepit }\end{array}$ & Cidera tangan & 1 & 3 & 3 & Moderate & $\begin{array}{l}\text { Penggunaan sarung } \\
\text { tangan safety }\end{array}$ & $\begin{array}{l}\text { Memebuat intruksi } \\
\text { kerja }\end{array}$ \\
\hline & & & & $\begin{array}{l}\text { Tertimpa } \\
\text { benda }\end{array}$ & Cidera kaki & 1 & 3 & 3 & Moderate & $\begin{array}{l}\text { Penggunaan sarung } \\
\text { sepatu safety }\end{array}$ & $\begin{array}{l}\text { Memasang } \\
\text { simbolsimbol } \\
\text { tanda bahaya }\end{array}$ \\
\hline & & & & Tergores & $\begin{array}{l}\text { Cidera tangan } \\
\text { dan kaki }\end{array}$ & 2 & 3 & 6 & Substansial & $\begin{array}{l}\text { Penggunaan sarung } \\
\text { tangan safety }\end{array}$ & - \\
\hline \multirow[t]{2}{*}{6} & Perakitan & & & $\begin{array}{l}\text { Tangan } \\
\text { tergores }\end{array}$ & $\begin{array}{l}\text { Luka kaki } \\
\text { dan tangan }\end{array}$ & 1 & 3 & 3 & Moderate & $\begin{array}{l}\text { Penggunaan sarung } \\
\text { tangan safety }\end{array}$ & $\begin{array}{l}\text { Memebuat intruksi } \\
\text { kerja }\end{array}$ \\
\hline & & & & $\begin{array}{l}\text { Tangan } \\
\text { tertimpa } \\
\text { benda kerja }\end{array}$ & $\begin{array}{l}\text { Cidera pada } \\
\text { kaki }\end{array}$ & 1 & 3 & 3 & Moderate & $\begin{array}{l}\text { Penggunaan sarung } \\
\text { sepatu safety }\end{array}$ & $\begin{array}{l}\text { Memasang } \\
\text { symbol-simbol } \\
\text { tanda bahaya }\end{array}$ \\
\hline
\end{tabular}

\subsection{Penetapan Obyektif, Target dan Program}

Berdasarkan hasil identifikasi bahaya dan penilaian risiko pada PT Unindo Pasifik seperti yang terdapat pada tabel 3 tersebut diatas maka telah diketahui bahaya dan risiko yang terdapat pada Departemen Fabrikasi. Untuk mengurangi terjadinya bahaya maka ditetapkanlah Objective, Target dan Program (OTP). OTP dapat juga disebut sebagai sasaran perusahaan yang harus ditinjau ulang secara periodik untuk mengetahui efektivitas 
pengendalian operasional terhadap bahaya. Tabel 4 dibawah ini merupakan OTP yang telah ditetapkan.

Tabel 2. Objective, Target dan Program (OTP)

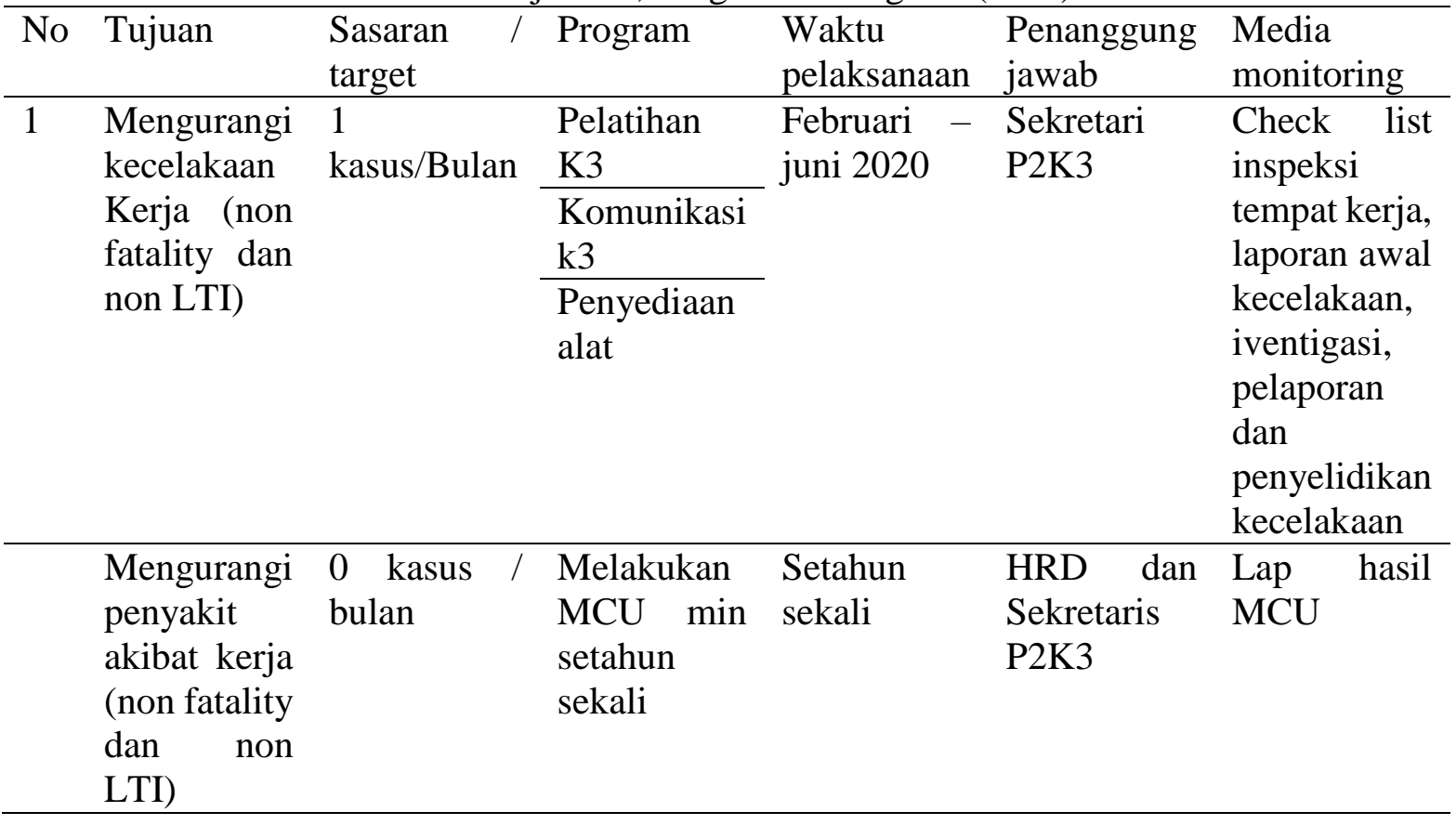

\section{Kesimpulan dan Saran}

Berdasarkan analisa dan pembahasan maka dapat ditarik senuah simpulan dari penelitian ini yaitu;

1. Terdapat empat kategori bahaya yaitu ektrim terdapat 3 Kriteria bahaya, high terdapat 10 kriteria bahaya, Moderate terdapat 8 kriteria bahaya dan low terdapat 2 kriteria bahaya

2. Pada Departemen Fabrikasi terdapat bahaya dan penyakit akibat kerja yang dapat ditimbukan pada setiap aktivitas pekerjaan. Untuk dapat meminimalisasi telah dilakukan pengendalian risiko berupa pengendalian administratif dan pengadaan APD.

3. Objective, Target dan Program (OTP) yang ditetapkan sebagai sasaran yang ingin dicapai yaitu mengurangi kecelakaan kerja (non fatality dan non LTI) sebesar 1 Kasus/Bulan dan mengurangi penyakit akibat kerja (non fatality dan non LTI) sebesar 0 Kasus/Bulan.

\section{Daftar Pustaka}

[1] E. Henri Ponda, "IDENTIFIKASI BAHAYA, PENILAIAN DAN PENGENDALIAN RISIKO KESELAMATAN DAN KESEHATAN KERJA (K3) PADA DEPARTEMEN FOUNDRY PT. SICAMINDO, jurnal teknik industri heuristtic Vol. 16 no. 2, hal. 62-74 . untag," pp. 62-74, 2019.

[2] E. Ngatijo, "PENILAIAN RESIKO K3 PADA PENGUJIAN KANDUNGAN URANIUM MENGGUNAKAN ALAT TITROPROSESOR, jurnal No. 16/Tahun IX. Pusat Teknologi Bahan Bakar Nuklir Badan Tenaga Nuklir Nasional, Serpong, Banten, Indonesia," no. 16, pp. 44-57, 2016. 
[3] A. Y. Tripariyanto, "Penerapan Metode HIRA dan Fishbone Diagram Pada Praktek Siswa SMK Yang Menimbulkan Risiko Kecelakaan Kerja Pada Bengkel Ototronik SMK, jurnal JATI UNIK, 2020, Vol.3, No.2,Hal :74-86,” vol. 3, no. 2, pp. 74-86, 2020.

[4] E. Feris Hanafi, "HAZARD IDENTIFICATION, RISK ASSESSMENT, AND RISK CONTROLAT VEHICLE BODY CONSTRUCTION AUTOMOTIVE WORKSHOPENGINEERING FACULTY UNY, jurnal pendidikan teknik otomotif edisiXVI, No.2," pp. 46-54, 2016.

[5] E. M. Triwibowo, Cecep \& Pusphandini, "Kesehatan Lingkungan Dan K3. Yogyakarta: Nuha Medika," no. 50, p. 18001, 2013.

[6] P. N. 5. tahun 2012, "Peraturan Pemerintah No. 50 Tahun 2012 'Penerapan Sistem Manajemen K3'.," no. 50, p. 2012, 2012.

[7] L. F. and A. S. Wahyuningsih, "Penerapan Sistem Manajemen Keselamatan dan Kesehatan Kerja (SMK3) di PT. Ahmadaris,' HIGEIA (Journal Public Heal. Res. Dev., vol. 1, no. 1, pp. 29-35," vol. 1, no. 1, p. 2017, 2017.

[8] O. E. Williamson et al., "CAPACIDADES DINÂMICAS COMO DIFERENCIAL ESTRATÉGICO PARA A SUSTENTABILIDADE,” J. Bus. Res., 2016.

[9] A. C. Ahmad, I. N. M. Zin, M. K. Othman, and N. H. Muhamad, "Hazard Identification, Risk Assessment and Risk Control (HIRARC) Accidents at Power Plant," MATEC Web Conf., vol. 66, pp. 1-6, 2016.

[10] P. Pradhan, "A HIRARC MODEL FOR SAFETY AND RISK AT I nternational J ournal of E ngineering $\mathrm{R}$ esearches and $\mathrm{M}$ anagement $\mathrm{S}$ tudies," IJERMS, vol. 3, no. 6, pp. 23-34, 2016.

[11] Gunawan, "Manajemen Keselamatan Operasi. Jakarta: Kompas Gramedia.,” p. 2016, 2016.

[12] R. Soehatman, “Manajemen Kebakaran. Jakarta: Dian Rakyat.,” p. 2010, 2010.

[13] C. D. Sucipto, "Keselamatan dan Kesehatan Kerja. Yogyakarta: Gosyen Publishing," no. 50, p. 18001, 2014.

[14] P. K. Marhavilas, M. Filippidis, G. K. Koulinas, and D. E. Koulouriotis, "A HAZOP with MCDM based risk-assessment approach: Focusing on the deviations with economic/health/environmental impacts in a process industry," Sustain., vol. 12, no. $3,2020$.

[15] T. Abbasi and S. A. Abbasi, "Role of HAZOP in assessing risk of accidents in chemical process industries : capability and lacunae," vol. 7, no. December 1984.

[16] S. Zare, M. R. Baneshi, R. Hemmatjo, S. Ahmadi, M. Omidvar, and B. F. Dehaghi, "The Effect of Occupational Noise Exposure on Serum Cortisol Concentration of Night-shift Industrial Workers: A Field Study," Saf. Health Work, vol. 10, no. 1, pp. 109-113, 2019.

[17] A. Musyafa and H. Adiyagsa, "Hazard and Operability study in Boiler System of The Steam Power Plant,” Int. J. Sci. Technol. (IJSTE), vol. 1, no. 3, pp. 1-10, 2012.

[18] Vishwas H SG D Gidwani, "Hazards Identification and Risk Assessment in Metro 
Railway Line Construction Project at Hyderabad," Int. J. Eng. Res., vol. V6, no. 08, pp. 243-249, 2017.

[19] P. Baybutt, "A critique of the Hazard and Operability (HAZOP) study," J. Loss Prev. Process Ind., 2015.

[20] S. Rahayuningsih and J. A. Pradana, "Identifikasi Penerapan Dan Pemahaman Kesehatan Dan Keselamatan Kerja Dengan Metode Hazard And Operability Study (Hazop) Pada UMKM Eka Jaya," JATI UNIK J. Ilm. Tek. dan Manaj. Ind., vol. 2, no. 1, p. 20, 2019.

[21] sugiyono, Metode Penelitian Kuantitatif, Kualitatif Dan R\&D. Bandung: CV Alfabeta. 2016.

[22] A.Maksum, "Data, Teknik Pengumpulan Data dan Instrumen Penelitian," J. Cakrawala Kependidikan,” 2012. 